Elżbieta Osewska

Cardinal Stefan Wyszynski University in Warsaw, Poland

\title{
Augusto Sarmiento, Małżeństwo chrześcijańskie. Podręcznik teologii małżeństwa i rodziny, Kraków 2002
}

\author{
(Augusto Sarmiento, Die christliche Ehe. \\ Ein Lehrbuch der Ehe- und Familientheologie, Krakau 2002), \\ Verlag „M”, 451 Seiten, ISBN 83-7221-561-8
}

Die tiefgründige Gemeinschaft des Lebens und der ehelichen Liebe, die Gott selbst eingesetzt und nach Seinem Gesetzen geschaffen hat, lässt sich nicht von dem Ehebund trennen, dem Christus die Würde eines Sakraments verliehen hat. In den Schriften der Kirche lesen wir, dass das Ehebündnis, in welchem Mann und Frau zusammen eine lebenslange Gemeinschaft zu ihrem eigenen Wohl und für die Erziehung ihrer Nachkommen gründen, Kraft und Stärke aus dem Schöpfungsakt gewinnt. Für die Getauften jedoch trägt es größere Würde in sich, da es zu den Sakramenten des Neuen Bundes zählt. In einer so ausformulierten Definition der ehelichen Gemeinschaft sind alle wesentlichen Elemente enthalten, die festlegen, worin das Wesen dieser allgemein und seit Zeiten bekannten Institution besteht. Leider wird heute versucht, „neue”, alternative Formen des Zusammenlebens als gesellschaftsfähig zu betrachten. Es gibt eine Fülle verschiedener Paarmodelle: die Ehe auf Probe, die Ehe ohne Trauschein, homosexuelle Lebensgemeinschaften. Auch die Unauflöslichkeit der Ehe wird als „Konservierung der Familie aus dem 19. Jahrhundert" in Frage gestellt. Daneben nimmt man den Wert der Ehe als Sakrament nicht mehr wahr, der Ehebund wird lediglich als zivilrechtlicher Vertrag betrachtet, den man auflösen kann. Von daher ist es in einer Epoche allgemeiner Werteliberalisierung unerlässlich, gerade auf diejenigen Werte zu verweisen, die das Ehe- und Familienleben wieder ordnen und regeln können.

Unter anderem aus diesen Gründen ergibt sich der Bedarf, die gesamte Bandbreite der Institutionen Ehe und Familie auf ganzheitliche, systematische und synthetische Art und Weise zu erörtern. In diesem Geist ist das Buch 
„Małżeństwo chrześcijańskie. Podręcznik teologii małżeństwa i rodziny” von Augusto Sarmiento, Professor für Moraltheologie an der Universität in Navarra, Spanien, zu betrachten. Der Autor unterzog in dieser Veröffentlichung die Problematik von Ehe und Familie einer ausführlichen Analyse - im Licht der christlichen Botschaft und unter Bezugnahme auf die Errungenschaften der humanistischen Wissenschaften. Christliche Lehre und Tradition, die mit dieser Thematik in Zusammenhang stehen, wurden mit Beobachtungen aus dem Alltag sowie mit teils interdisziplinären wissenschaftlichen Untersuchungen konfrontiert, die aufzeigen, dass Veränderungen auf dieser bedeutenden Ebene des Lebens weiter voranschreiten. „Als Wiege des Lebens und der Liebe, in der der Mensch geboren wird und wächst, stellt sie die Grundzelle der Gesellschaft dar" - der Versuch, diese vom Autor gewählten Worte Johannes Pauls II. über die Familie aus „Christifideles laici”, Nr. 40, zu interpretieren, scheint das Motiv für die Entstehung der vorliegenden Arbeit gewesen zu sein.

Das rezensierte Buch umfasst eine Einführung, neun Teile mit insgesamt 24 Kapiteln und die Bibliographie. Die ersten acht Teile befassen sich mit der Ehe, während das neunte näher auf die Familie eingeht. Jeder Teil beginnt mit einer Einleitung, in welcher Intention, Quellen und Perspektiven des besprochenen Fragenkreises erläutert werden. In seiner Einführung beruft sich A. Sarmiento auf die Schriften Johannes Pauls II. und präsentiert damit Problemstellung und Ziel seiner Arbeit. Dadurch wird der Leser gut an den Inhalt des Buches und den Ernst der vorgestellten Thematik herangeführt.

Die Ehe hat ihre Wurzeln in der Existenz des Menschen als Mann und Frau, was von Anfang an Teil des Göttlichen Plans für die Menschheit war. Die Ehe ist diejenige Institution, in welcherderMensch seineBerufung zurLiebe verwirklichen kann. Nach der Darlegung der anthropologischen Wurzeln der Institution Ehe (erster Teil) zieht der Autor im Erlösungswerk Gottes Schlussfolgerungen aus jener Thematik, indem er gewissermaßen an den „Anbeginn” zurückgeht. Gott hat den Menschen aus Liebe ins Dasein berufen, damit ist dieser gleichzeitig auch zur Liebe berufen. Die grundlegende Wahrheit über die Ehe verweist auf Gott als ihren Schöpfer. Im Unterschied zu den weiteren Sakramenten stellt die Ehe eine Wirklichkeit des „Anbeginns” dar, da sie als Göttliche Institution bereits vor dem Erscheinen Christi in der Welt existiert (zweiter Teil). Das Geheimnis der christlichen Ehe lässt sich schwerlich ohne den Blick auf den Neuen Bund verstehen, der sich in der Person Jesu Christi erfüllt hat. Das Sakrament der Ehe stellt Gnade und Würde dar, die der Kirche durch das Heilswerk Gottes für den Menschen gespendet sind. Zwischen dem Ehebund und dem Liebesbund Gottes mit den Menschen besteht eine innere Analogie - eine gegenseitige Beziehung und 
Implikation. Als Sakrament ist die Ehe ein Wirken Christi, ein Zeichen, welches Gnade bedeutet und schenkt - nicht nur Gnade verheißt (dritter Teil).

Die kirchliche Feier der Hochzeit erfordert es, das zelebrierte Mysterium zu kennen und sich bei der Begehung der Feier aktiv zu engagieren, was eine entsprechende Vorbereitung voraussetzt. Diese Vorbereitung aufdas Ehesakrament stellt für die Kirche eine besondere Form und einen spezifischen Aspekt der Evangelisierungdar. Quelle und verantwortlicher Initiator der Ehevorbereitung ist die Kirche selbst (vierter Teil). Der Ehebund, der aus dem Ehesakrament heraus gelebt wird, ist das wirkliche Zeichen der Beziehung Jesu zur Kirche, als seiner Braut. Jenes Sakrament bezeichnet und konsekriert die Ehegatten, dadurch geht die eheliche Liebe eine Verbindung mit der Liebe Gottes ein. Das Ehesakrament ist auch ein wirkungsvolles Zeichen der Gnade und die Quelle dafür, dass sich die Eheleute durch ihre gegenseitige Liebe und ihre Hingabe an den anderen heiligen (fünfter Teil). Einigkeit und Unauflöslichkeit bezeichnen den Ehestand, sie sind also absolut unverzichtbare Merkmale. Der Autor bringt diese Wesenszüge mit der ehelichen Liebe in Verbindung, indem er sich auf das Magisterium der Kirche beruft (sechster Teil).

Das Führen einer christlichen Ehe nach dem Evangelium kostet Anstrengung und Kraftaufwand, um all das zu überwinden, was dem Wohl und der Wahrheit entgegensteht. Die modernen materialistischen und hedonistischen Angebote, welche die Rechtfertigung ungeregelter Verhältnisse von Paaren begünstigen oder sogar empfehlen, erhöhen diese Schwierigkeiten. Diese Betrachtung ergänzte der Autor mit Reflexionen über einige besondere Situationen im Rahmen des ehelichen Bundes (siebter Teil). Im Anschluss daran stellte der den Zweck der Ehe aus der Perspektive ihrer Wesensmerkmale vor, indem er zunächst ein historisches Panorama bezüglich der Ziele ehelicher Gemeinschaft in verschiedenen Epochen zeichnete. Von fundamentaler Bedeutung ist dabei das zweifache Ziel der Ehe: Die Ehe und die eheliche Liebe sind aus ihrer Natur heraus ausgerichtet auf die Geburt und die Erziehung der Kinder sowie auf das Wohlergehen und die gegenseitige Hilfe der Ehegatten (achter Teil). Der Schlussteil verweist auf die durch nichts zu ersetzende Rolle der Familie bei der Entwicklung und der Hinführung zu Gesellschaft und Kirche. Die Gesellschaft wird nur so gestaltet sein, wie es die Familie ist (neunter Teil).

Ein großer Vorzug des besprochenen Buches ist die geradezu penible Bezugnahme auf eine Vielzahl von Quellen zu diesem Thema und deren Konfrontation mit zahlreichen zitierten Dokumenten der Kirche. Die jedem Kapitel angefügte Bibliographie lässt zu der Feststellung führen, dass es sich um ein sehr gut ausgearbeitetes wissenschaftliches Lehrbuch handelt, das aus 
verständlichen Gründen in einer „schwierigen” wissenschaftlichen Sprache abgefasst ist und sich überwiegend an Studenten und solche Leser richtet, die sich mit der Familienberatung beschäftigen, aber mit Sicherheit auch an Seelsorger, Katecheten, verlobte Paare, Ehepartner und Eltern. Ebenso ist die am Schluss der Veröffentlichung angefügte reichhaltige Bibliographie überaus zu schätzen, die sowohl in spanischer als auch in polnischer Sprache vom polnischen Verfasser erstellt worden ist. Obwohl es zu dem präsentierten Thema bereits viele Publikationen gibt, ist das rezensierte Buch dennoch im Hinblick auf die Bedeutung, auf die umfassende Betrachtung und vor allem auf die meritorische Qualität der aufgegriffenen Thematik umso mehr zu würdigen und verdient allgemeine Beachtung. 